\begin{abstract}
Iranica
Abstracta Iranica Revue bibliographique pour le domaine irano-aryen

Volume 34-35-36 | 2017

Comptes rendus des publications de 2011-2013
\end{abstract}

\title{
Zeeya A. Pashtoon. Pashto-English Dictionary
}

\section{Matteo De Chiara}

\section{(2) OpenEdition}

Journals

Édition électronique

URL : http://journals.openedition.org/abstractairanica/41142

DOI : 10.4000/abstractairanica.41142

ISSN : 1961-960X

Éditeur :

CNRS (UMR 7528 Mondes iraniens et indiens), Éditions de l'IFRI

\section{Référence électronique}

Matteo De Chiara, «Zeeya A. Pashtoon. Pashto-English Dictionary », Abstracta Iranica [En ligne], Volume 34-35-36 | 2017, document 1, mis en ligne le 15 février 2016, consulté le 02 octobre 2020. URL : http:// journals.openedition.org/abstractairanica/41142; DOI : https://doi.org/10.4000/abstractairanica. 41142

Ce document a été généré automatiquement le 2 octobre 2020.

Tous droits réservés 


\title{
Zeeya A. Pashtoon. Pashto-English Dictionary
}

\author{
Matteo De Chiara
}

\section{RÉFÉRENCE}

Zeeya A. Pashtoon. Pashto-English Dictionary. First Edition, Hyattsville, Dunwoody Press, 2009, vi+853 p.

1 Le dictionnaire pashto-russe de M.G. Aslanov (Afgansko-russki slovar'. Moskva, 1966) demeure encore aujourd'hui, à presque 50 ans de sa publication, une référence indispensable pour la pashtologie internationale. Cette première édition du PashtoEnglish Dictionary représente quasiment la traduction littérale de cet ouvrage : cela va sans dire, un outil utile et très commode, voire essentiel pour tous ceux qui ne sont pas en mesure de lire le russe. Les 60000 mots contenus à l'intérieur en font le plus consistant dictionnaire bilingue du pashto. Dans chaque entrée, on peut trouver le mot en graphie pashto, transcription, codage grammatical, renseignements grammaticaux si nécessaires, source dialectale ou étymologique si spécifiée, glose anglaise et phraséologie. Tâche énorme et travail titanique, les coquilles et les petites fautes n'en diminuent absolument pas la valeur. On aurait peut-être aidé à la lecture en mettant en italique la transcription des mots. L'oubli, parfois de la graphie pashto ou du codage

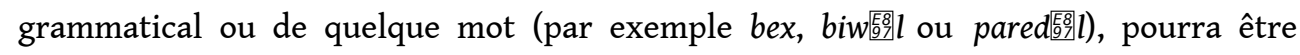
remédié dans la deuxième édition, en préparation, qui « will be corpus-based and will include new headwords, new definitions, and new examples » et qui en fera sans doute la meilleure source lexicographique existante pour le pashto. 


\section{AUTEURS}

MATTEO DE CHIARA

INaLCO, Mondes Iranien et Indien, Paris 